\title{
Efisiensi Mikroenkapsulasi Ekstrak Kulit Buah Naga Super Merah (Hylocereus costaricensis) Tersalut Maltodekstrin Berdasarkan Kecepatan Pengadukan
}

\section{[Microencapsulation Efficiency of Super Red Dragon Fruit (Hylocereus costaricensis) Peel Extract Coated with Maltodextrin Based on Stirring Speed]}

\author{
Jaya Hardi ${ }^{1}$, Dian Citra ${ }^{1 *}$, Syamsuddin ${ }^{1}$, Dwi Juli Puspitasari ${ }^{1}$ \\ 1) Jurusan Kimia, Fakultas MIPA, Universitas Tadulako, Jl.Soekarno-Hatta Km.9, Kampus Bumi Tadulako Tondo Palu
}

*)Coresponding author: diancitra013@gmail.com

\begin{abstract}
Extract of super red dragon fruit peel has an antioxidant activity that can prevent free radicals from outside and its activity can be maintained by the coating of super red dragon fruit peel extract with maltodextrin The coating efficiency of super red dragon fruit peel extract with maltodextrin can be controlled with the speed of stirring during microencapsulation experiment. In order to obtain the highest microencapsulation efficiency and compare the antioxidant activity of super red dragon fruit peel extract before and after microencapsulation experiment. The study of coating efficiency has been done with microencapsulation that was carried out using the freeze-drying technique. During the microencapsulation of super red dragon fruit peel extract with freeze-drying technique, stirring speed in the microencapsulation process was $600 \mathrm{rpm}, 800 \mathrm{rpm}, 1000 \mathrm{rpm}, 1200 \mathrm{rpm}$, and $1400 \mathrm{rpm}$ respectively. From the microencapsulation process of super red dragon fruit peel extract coated with maltodextrin, it was obtained the highest microencapsulation efficiency at stirring speed of $800 \mathrm{rpm}$, which was $66.85 \%$ and had a particle size of $14.24 \mu \mathrm{m}$. It can be concluded that the antioxidant activity before and after encapsulation included a very weak category with $\mathrm{IC}_{50}$ values of $205.42 \mathrm{ppm}$ for extracts and $246.32 \mathrm{ppm}$ for microcapsules.
\end{abstract}

Keywords: Super red dragon fruit peel, freeze-drying, microencapsulation, maltodextrin

ABSTRAK. Ekstrak kulit buah naga super merah memiliki kandungan antioksidan yang dapat menangkal radikal bebas dari luar dan aktivitasnya dapat dipertahankan dengan cara melakukan penyalutan menggunakan maltodekstrin. Efisiensi penyalutan ekstrak kulit buah naga super merah dengan maltodekstrin dapat dipengaruhi oleh kecepatan pengadukan selama proses mikrokapsulasi. Tujuannya adalah untuk memperoleh efisiensi mikroenkapsulai tertinggi dan membandingkan aktivitas antioksidan ekstrak kulit buah naga super merah sebelum dan setelah proses enkapsulasi. Selama mikroenkapsulasi ekstrak kulit buah naga super merah dengan teknik pengeringan beku, kecepatan pengadukan adalah 600 rpm, 800 rpm, 1000 rpm, 1200 rpm, dan $1400 \mathrm{rpm}$. Proses mikroenkapsulasi ekstrak kulit buah naga super merah dengan maltodekstrin, diperoleh efisiensi mikroenkapsulasi tertinggi pada kecepatan pengadukan $800 \mathrm{rpm}$, yaitu $66,85 \%$ dan memiliki ukuran partikel $14,24 \mu \mathrm{m}$. Dapat disimpulkan bahwa aktivitas antiokskidan sebelum dan setelah terkapsulasi termasuk kategori sangat lemah dengan nilai IC ${ }_{50}$ sebesar 205,42 ppm untuk ekstrak dan 246,32 ppm untuk mikrokapsul.

Kata kunci: Kulit buah naga super merah, pengeringan beku, mikroenkapsulasi, maltodekstrin

Riwayat artikel: Diterima 1 Mei 2019, Disetujui 9 April 2020

Cara sitasi: Hardi, J., Citra, D., Syamsuddin., Puspitasari, D J. (2020). Efisiensi Mikroenkapsulasi Ekstrak Kulit Buah Naga Super Merah (Hylocereus costaricensis) Tersalut Maltodekstrin Berdasarkan Kecepatan Pengadukan. KOVALEN: Jurnal Riset Kimia, 6(1): 1-8.

DOI: https://doi.org/10.22487/kovalen.2020.v6.i1.12647 


\section{LATAR BELAKANG}

Tanaman buah naga merupakan salah satu jenis tanaman kaktus yang dapat tumbuh dan berkembang dengan baik di daerah tropis salah satunya di Indonesia (Hardjadinata, 2010). Buah naga memiliki empat varietas, yaitu buah naga daging merah (Hylocereus polyrhizus), daging super merah (Hylocereus costaricensis), daging putih (Hylocereus undatus), dan kulit kuning daging putih (Selenicereus megalanthus) (Cahyono, 2009). Kulit buah naga mengandung beberapa metabolit sekunder, diantaranya ialah vitamin A, B, C, dan E, karotenoid, flavonoid, piridoksin, fenolik serta fitoalbumin (Jaafar et al., 2009). Menurut Wu et al. (2006), kulit buah naga memiliki keunggulan kaya akan polifenol dan sumber antioksidan.

Kulit buah naga memiliki aktivitas antioksidan yang lebih besar dibandingkan aktivitas antioksidan pada daging buahnya. Nurliyana et al. (2010), melaporkan bahwa 1 $\mathrm{mg} / \mathrm{ml}$ kulit buah naga merah memiliki kemampuan menghambat radikal bebas hingga $83,48 \pm 1,02 \%$, atau jauh lebih tinggi dibandingkan dengan daging buahnya yang hanya mampu menghambat 27,45 $\pm 5,03 \%$ radikal bebas. Menurut Pokorny et al. (2001), stabilitas antioksidan dipengaruhi oleh faktor luar seperti oksigen, cahaya, kelembapan dan pemanasan, hal ini menyebabkan antioksidan tidak stabil pada penyimpanan. Untuk menjaga kestabilan tersebut dapat dilakukan teknik enkapsulasi.

Enkapsulasi didefiniskan sebagai teknik penyalutan bahan aktif menggunakan bahan atau senyawa penyalut. Ada beberapa jenis penyalut yang biasa digunakan pada pembuatan mikrokapsul diantaranya hidroksipropil metilselulosa, gum arab, pati termodifikasi dan maltodekstrin. Penyalut yang cukup potensial digunakan adalah maltodekstrin. Pemilihan maltodekstrin sebagai penyalut dikarenakan maltodekstrin mampu membentuk emulsi, memiliki viskositas rendah, mudah bercampur dengan air, ketika dipanaskan dapat membentuk cairan koloid dan tidak toksik (Welsh, 2001 dalam Irsyad, 2017). Jenis enkapsulasi berdasarkan ukuran partikel terdiri dari makrokapsul, mikrokapsul dan nanokapsul (Winarno, 2017). Pada umumnya untuk ekstrak dari tanaman menggunakan teknik mikrokapsulasi. Irsyad (2017), telah melakukan penelitian mengenai mikrokapsul antosianin dari kelopak bunga rosella dengan menggunakan penyalut maltodekstrin, hasil yang diperoleh yaitu rasio antosianin kelopak bunga rosella tersalut maltodekstrin memiliki rendemen tertinggi pada rasio $1: 1$ yaitu sebesar $49,05 \%$.

Handayani et al. (2018) melaporkan bahwa kulit buah naga merah diekstraksi menggunakan pelarut polar $\mathrm{pH} 4$ dan $\mathrm{pH} 5$ dengan metode maserasi dan dapat disalut menggunakan maltodekstrin. Hasil penelitiannya menunjukkan rasio maltodekstrin terhadap ekstrak kulit buah naga merah 5:1 lebih efisien dibandingkan rasio 3:1. Morfologi mikrokapsul ekstrak kulit buah naga berbentuk matriks dengan diameter partikel antara 0,4600,770 $\mu \mathrm{m}$, sedangkan diameter partikel ekstrak kulit buah naga dengan $\mathrm{pH} 4$ antara 0,288-0,640 $\mu \mathrm{m}$.

Selain rasio ekstrak dan penyalut, pembentukan mikrokapsul juga dipengaruhi oleh kecepatan pengadukan yang akan mempengaruhi ukuran partikel pada mikrokapsul (Neswita et al., 2018). Rendahnya kecepatan pengadukan akan menghasilkan mikrokapsul yang berukuran besar, begitupun 
sebaliknya tingginya kecepatan pengadukan akan menghasilkan mikrokapsul yang berukuran kecil (Sutriyo et al., 2004).

$$
\text { Kecepatan penagdukan juga }
$$

berpengaruh pada efisiensi penyalutan. Silitonga \& Sitorus (2014), melaporkan hasil penelitiannya mengenai enkapsulasi pigmen antosianin dari kulit terong ungu menggunakan metode koaservasi dengan variasi konsentrasi maltodekstrin sebagai penyalut dan kecepatan pengadukan, hasil yang diperoleh yaitu kondisi optimum enkapsulasi berada pada konsentrasi maltodekstrin $50 \%$ dan kecepatan pengadukan $600 \mathrm{rpm}$ dengan efisiensi enkapsulasi tertinggi yaitu $63,85 \%$. Penelitian lebih lanjut perlu dilakukan untuk melihat pengaruh kecepatan agitasi terhadap efisiensi penyalutan dan untuk mengetahui seberapa besar aktivitas antioksidan pada ekstrak etanol kulit buah naga tersalut maltodekstrin.

\section{METODE PENELITIAN}

\section{Bahan dan Peralatan}

Bahan yang digunakan yaitu kulit buah naga super merah (Hylocereus costaricensis) sebagai sampel penelitian. Bahan kimia yang digunakan etanol $96 \%, \mathrm{HCl} 1 \%$, aquades, DPPH. dan maltodekstrin.

Alat yang digunakan yaitu aluminium foil, blender, ayakan 60 mesh, neraca analitik Ohaus Corp. Pine Brook, mesin agitasi, pipet volum, pipet gondok, desikator, radas penguap putar, oven, pengering beku (Freeze-dryer), reaktor berpengaduk, Scanning Electron Microscopy (SEM) HITACHI FLEXSEM 100, dan Spektrofotometer UV-Vis PerkinElmer L850.

\section{Prosedur Penelitian}

\section{Preparasi sampel}

Sampel buah naga dikupas dan dibersihkan untuk memisahkan daging buah dengan kulitnya, selanjutnya kulit buah dicuci dan dikeringkan dengan sinar matahari hingga benar-benar kering. Kulit buah naga dihancurkan dengan blender, kemudian diayak dengan menggunakan ayakan 60 mesh hingga diperoleh tepung buah naga.

\section{Ekstraksi kulit buah naga}

Sejumlah $500 \mathrm{~g}$ sampel kulit buah naga yang telah halus diekstraksi dengan teknik maserasi menggunakan pelarut etanol 96\% dan $\mathrm{HCl} 1 \%$ dengan perbandingan volume 9 : 1 sebanyak $1000 \mathrm{~mL}$. Maserasi dilakukan selama 1x24 jam pada suhu ruang, kemudian disaring dan filtratnya ditampung. Ekstraksi dilakukan berulang sampai seluruh pigmen antosianin pada kulit buah naga terekstraksi sempurna (Putri et al., 2015). Filtrat tersebut diuapkan dengan menggunakan radas penguap putar, sehingga didapat ekstrak kental etanol kemudian ditimbang beratnya dan disimpan di lemari pendingin sebelum dilakukan mikroenkapsulasi.

\section{Mikroenkapsulasi ekstrak kulit buah naga}

Mikroenkapsulasi ekstrak kulit buah naga dilakukan dengan menggunakan metode Priya \& Preetha (2016) dengan beberapa modifikasi, maltodekstrin dilarutkan dengan aquades perbandingan (1:1). Kemudian ekstrak etanol kulit buah naga ditambahkan ke dalam larutan maltodekstrin sambil diaduk dengan reaktor berpengaduk pada suhu ruang dengan variasi kecepatan 600 rpm, 800 rpm, 1000 rpm, 1200 rpm, dan 1400 rpm selama 30 menit. Rasio antara ekstrak dengan maltodekstrin yang digunakan yaitu 1:4 (b/b). Campuran mikroemulsi selanjutnya diubah menjadi mikrokapsul dengan menggunakan alat freeze-drying, serbuk yang didapatkan selanjutnya ditentukan efisiensi penyalutannya. 


\section{Analisis efisiensi mikroenkapsulasi}

Mikrokapsul digerus sebanyak 0,5 g dan diekstraksi dengan $10 \mathrm{~mL}$ etanol 96\%, kemudian disaring dan filtratnya dipekatkan dengan menggunakan radas penguap putar, ekstrak pekat yang diperoleh kemudian dioven dan ditimbang. Efisiensi mikroenkapsulasi ditentukan dengan menggunakan Persamaan 1 (Hardi et al., 2013).

$$
\operatorname{EP}(\%)=\frac{M m-M k \times \frac{a}{b}}{M e} \times 100
$$

Keterangan :

$$
\begin{aligned}
& \mathrm{EP}=\text { Efisiensi mikroenkapsulasi/penyalutan } \\
& \mathrm{a}=\text { Massa mikrokapsul total }(\mathrm{g}) \\
& \mathrm{b}=\text { Massa mikrokapsul yang dianalisis }(\mathrm{g}) \\
& \mathrm{Mm}=\text { Massa ekstrak mikrokapsul }(\mathrm{g}) \\
& \mathrm{Mk}=\text { Massa kontrol }(\mathrm{g}) \\
& \mathrm{Me}=\text { Massa awal ekstrak kulit buah naga }(\mathrm{g})
\end{aligned}
$$

Selanjutnya mikrokapsul dengan nilai efisiensi tertinggi ditentukan dengan morfologi dan ukurannya dengan menggunakan alat Scanning Electron Microscopy (SEM).

\section{Uji aktivitas antioksidan dengan metode $D P P H$}

Ekstrak etanol dan mikrokapsul ditimbang sebanyak $25 \mathrm{mg}$ dan dimasukkan ke dalam labu ukpur $25 \mathrm{ml}$, kemudian ditambahkan etanol, dan ditepatkan volumenya sehingga diperoleh konsentrasi 1000 ppm sebagai larutan stok. Larutan stok diencerkan untuk menghasilkan larutan dengan konsentrasi masing-masing 10 ppm, 30 ppm, 50 ppm, 70 ppm, 90 ppm. Untuk penentuan aktivitas antioksidan masing-masing konsentrasi dipipet sebanyak 0,2 $\mathrm{ml}$ larutan sampel dengan pipet mikro dan dimasukkan ke dalam tabung reaksi kemudian ditambahkan 3,8 ml larutan DPPH. Campuran dihomogenkan dan dibiarkan selama 30 menit ditempat gelap, serapan diukur dengan spektrofotometer UV-Vis pada panjang gelombang $517 \mathrm{~nm}$ (Amar et al.,
2018). Selain itu dilakukan pula pengukuran kontrol. Aktivitas antioksidan yang dinyatakan dalam satuan persen inhibisi (Persamaan 2).

$$
\% \text { inhibisi }=\frac{A k-A s}{A k} \times 100
$$

$$
\text { Keterangan: } \mathrm{Ak}=\text { absorbansi DPPH }
$$$$
\text { As }=\text { Absorbansi sampel }
$$

\section{HASIL DAN PEMBAHASAN}

\section{Ekstrak Kulit Buah Naga Super Merah (Hylocereus costaricensis)}

Proses ekstraksi kulit buah naga super merah dilakukan untuk memisahkan kandungan kimia yang terdapat pada kulit buah naga super merah dengan menggunakan pelarut organik. Pada proses ini digunakan metode maserasi dengan pelarut etanol $96 \%$ dan $\mathrm{HCl} 1 \%$. Penambahan $\mathrm{HCl}$ dalam etanol dikarenakan senyawa antosianin bersifat stabil dalam suasana asam. Sehingga pada proses maserasi dilakukan akan menghasilkan kandungan antosianin pada kulit buah naga super merah menghasilkan 85,6 g ekstrak kental etanol yang berwarna merah pekat.

\section{Efisiensi Mikroenkapsulasi}

Perhitungan efisiensi mikroenkapsulasi digunakan untuk mengetahui tingkat keberhasilan proses mikroenkapsulasi. Efisiensi yang dimaksud dalam penelitian ini merupakan kecepatan pengadukan yang digunakan saat melakukan mikroenkapsulasi.

Efisiensi mikrokapsul yang dihasilkan pada tiap kecepatan pengadukan $600 \mathrm{rpm}$, 800 rpm, 1000 rpm, 1200 rpm dan 1400 rpm masing-masing yaitu sebesar 59,71\%; $66,85 \%$; 61,48\%; 57,73\%; dan 55,91\% (Gambar 1). Berdasarkan penelitian yang dilakukan, kondisi optimum kecepatan pengadukan adalah $800 \mathrm{rpm}$ dengan nilai 
efisiensi mikrokapsul yang diperoleh, yaitu $66,85 \%$.

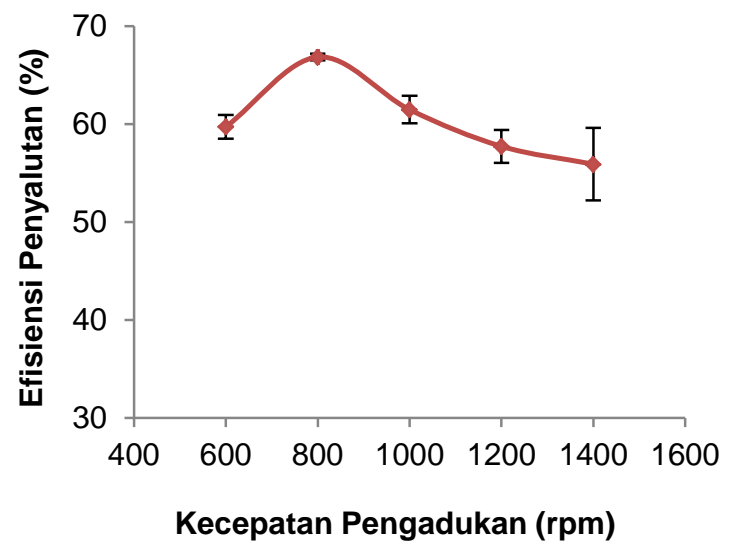

Gambar 1. Pengaruh kecepatan pengadukan mikrokapsul ekstrak kulit buah naga super merah terhadap efisiensi penyalutan.

Pada penelitian yang dilakukan oleh Silitonga \& Sitorus (2014) mengenai enkapsulasi pigmen antosianin dari kulit terong ungu dengan maltodekstrin menunjukkan hasil efisiensi enkapsulasi tertinggi pada kecepatan pengadukan 600 rpm dengan nilai efisiensi sebesar 63,85\%. Penelitian lainnya yang dilakukan oleh Pratama (2017) mendapatkan nilai efisiensi tertinggi sebesar $50,68 \%$ dengan kecepatan pengadukan $1000 \mathrm{rpm}$ pada enkapsulasi ekstrak daun mangrove (Avicennia marina).

Hasil penelitian ini menunjukkan bahwa terjadi peningkatan efisiensi yang tidak signifikan terhadap kecepatan pengadukan, Hal ini diduga disebabkan oleh kecepatan pengadukan yang tinggi menyebabkan senyawa antioksidan dalam mikrokapsul terdisolusi kembali ke lingkungannya.

Menurut Sutriyo et al. (2004) kecepatan pengadukan mempengaruhi bentuk serta ukuran partikel mikrokapsul. Semakin cepat proses pengadukan partikel enkapsulat yang diperoleh semakin kecil. Utama et al. (2013) juga menyatakan bahwa kecepatan pengadukan dapat mempengaruhi hasil kadar formula yang dihasilkan dan efisiensi penjerapan formula dikarenakan kecilnya partikel yang dihasilkan sehingga menyebabkan peluang lepasnya kembali zat yang terenkapsulasi semakin besar.

Berdasarkan hasil analisis statistik mengunakan metode One Way ANOVA menghasilkan nilai signifikan 0,018 atau lebih dari $\alpha(0,05)$, sehingga kecepatan pengadukan berpengaruh nyata terhadap efisiensi penyalutan. Hasil uji Duncan menunjukkan bahwa kecepatan pengadukan 1400, 1200, dan $600 \mathrm{rpm}$ berbeda tidak nyata. Kecepatan pengadukan $1400 \mathrm{rpm}$ dengan 1000 rpm berbeda nyata dan kecepatan pengadukan 1000 rpm dengan $800 \mathrm{rpm}$ berbeda nyata, sehingga penggunaan kecepatan $800 \mathrm{rpm}$, adalah perlakuan terbaik.

\section{Morfologi Mikrokapsul}

Pengamatan morfologi mikrokapsul terhadap mikrokapsul ekstrak kulit buah naga super merah dilakukan dengan menggunakan Scanning Electron Microscopy (SEM). Hasil pengamatan morfologi mikrokapsul ekstrak kulit buah naga super merah dengan SEM menunjukkan bahwa bentuk mikrokapsul adalah bulat atau spheric (Gambar 2).

Mikrokapsul mempunyai beberapa macam bentuk, salah satunya adalah berbentuk bulat. Morfologi mikrokapsul dapat diklasifikasikan menjadi 3 macam tipe, yaitu (i) mononuclear atau mikrokapsul yang mengandung bahan inti yang dikelilingi oleh bahan penyalut, (ii) polynuclear atau mikrokapsul yang mengandung beberapa bahan inti dalam penyalutnya, dan (iii) matriks atau mikrokapsul yang mengandung bahan inti yang terdispersi merata dalam bahan penyalut 
(Thies, 1996). Tipe mikrokaspul yang dihasilkan sangat memungkin sesuai dengan tipe ketiga.

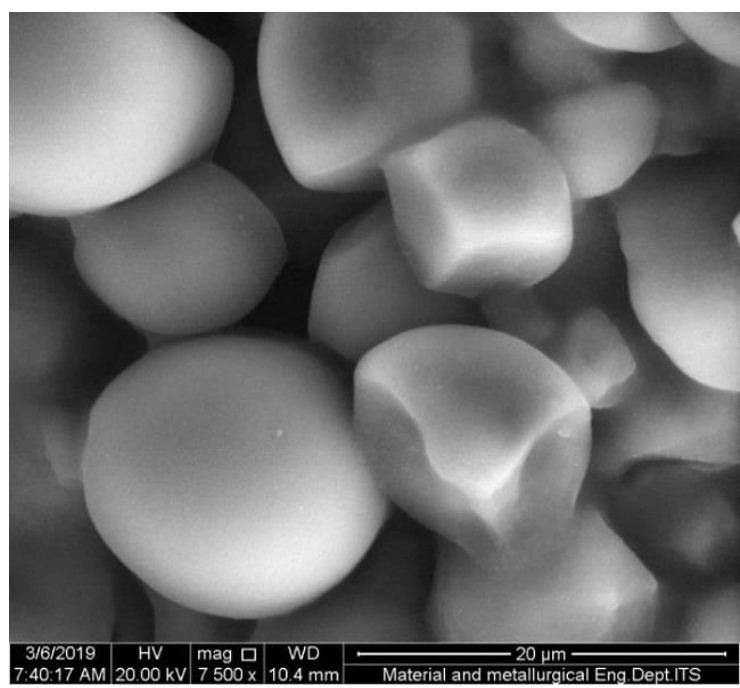

Gambar 2. Morfologi mikrokapsul ekstrak kulit buah naga super merah pada keecepatan pengadukan $800 \mathrm{rpm}$ perbesaran $7500 \mathrm{x}$.

Kecepatan pengadukan juga sangat berpengaruh pada ukuran partikel. Semakin cepat pengadukan selama enkapsulasi, maka partikel yang dihasilkan akan semakin kecil (Manjanna et al., 2010). Selain itu, jumlah penyalut yang digunakan dalam mikroenkapsulasi juga dapat mempengaruhi ukuran partikel yang dihasilkan (Comunian et al., 2013). Pada penelitian yang dilakukan, perhitungan partikel ditentukan dengan menggunakan software ImageJ dan diperoleh bahwa nilai rata-rata diameter mikrokapsul ekstrak kulit buah naga super merah, yaitu 14,24 $\mu \mathrm{m}$. Hasil yang diperoleh telah memenuhi persyaratan untuk ukuran partikel mikrokapsul yaitu antara 1-1000 $\mu \mathrm{m}$ (Trojer, 2012).

\section{Aktivitas Antioksidan Mikrokapsul Ekstrak Etanol Kulit Buah Naga Super Merah}

Aktivitas antioksidan mikrokapsul ekstrak etanol kulit buah naga super merah menggunakan metode predaman radikal DPPH dengan spektrofotometri UV-Vis pada panjang gelombang $517 \mathrm{~nm}$.

Tabel 1. Persen inhibisi mikrokapsul ekstrak etanol kulit buah naga super merah

\begin{tabular}{ccc}
\hline \multirow{2}{*}{$\begin{array}{c}\text { Konsentrasi } \\
\text { ekstrak } \\
\text { (ppm) }\end{array}$} & \multicolumn{2}{c}{ \% Inhibisi } \\
\cline { 2 - 3 } & $\begin{array}{c}\text { Ekstrak tanpa } \\
\text { penyalut }\end{array}$ & Mikrokapsul \\
\hline 10 & 7,81 & 3,23 \\
30 & 11,62 & 7,34 \\
50 & 17,97 & 10,76 \\
70 & 20,90 & 15,26 \\
90 & 24,71 & 19,08 \\
\hline
\end{tabular}

Pada konsentrasi $10 \mathrm{ppm}$, nilai persen inhibisinya adalah $7,81 \%$ untuk ekstrak etanol (kontrol) dan 3,23\% untuk mikrokapsul, sedangkan pada konsentrasi 30 ppm hanya meningkatkan persen inhibisi dari 7,81\% menjadi $11,62 \%$ (kenaikan 3,81\%) dan dari $3,23 \%$ menjadi $7,34 \%$ (kenaikan 4,11\%) (Tabel 1). Persen inhibisi dari ekstrak etanol kulit buah naga lebih tinggi daripada setelah penyalutan disebabkan karena peluang terjadinya disolusi senyawa antioksidan selama proses mikroenkapsulasi cukup besar. Amar (2018), juga melakukan uji aktivitas antioksidan pada mikrokapsul ekstrak etanol kapang oncom merah pada konsentrasi 10 ppm menghasilkan persen inhibisi sebesar $11,17 \%$ kemudian naik menjadi $13,50 \%$ pada konsentrasi $30 \mathrm{ppm}$ dan nilai $\mathrm{IC}_{50}$ sebesar 203,58 ppm.

Menurut Blois, aktivitas antioksidan dibagi menjadi beberapa kategori berdasarkan nilai $\mathrm{IC}_{50}$, yaitu sangat kuat, kuat, sedang, lemah, dan sangat lemah (Molyneux, 2004). Antioksidan dengan kategori sangat kuat memiliki nilai $\mathrm{IC}_{50}<50 \mathrm{ppm}$, kategori kuat memiliki nilai $\mathrm{IC}_{50}$ antara 50-100 ppm, kategori sedang memiliki nilai $\mathrm{IC}_{50}$ antara $100-150$ ppm, 
kategori lemah memiliki nilai $\mathrm{IC}_{50}$ antara 150 200 ppm dan kategori sangat lemah memiliki nilai $\mathrm{IC}_{50}$ lebih besar dari 200 ppm.

Berdasarkan hal itu, maka antioksidan ekstrak etanol kulit buah naga super merah termasuk kategori sangat lemah, begitupun pada mikrokapsul ekstrak kulit buah naga super merah, karena nilai $\mathrm{IC}_{50}$ lebih besar dari 200 ppm yaitu 205,42 ppm untuk ekstrak dan 246,32 ppm untuk mikrokapsul.

Widyastuti et al. (2015) telah melakukan pengujian aktivitas antioksidan ekstrak etanol kulit buah naga super merah menggunakan metode $\mathrm{DPPH}$, nilai $\mathrm{IC}_{50}$ yang dihasilkan yaitu 4602,740 ppm. Pranata et al. (2014) melakukan uji aktivitas antioksidan pada fraksi kloroform kulit buah naga super merah dengan metode DPPH, nilai $\mathrm{IC}_{50} \quad 3349,936$ ppm. Perbedaan aktivitas antioksidan terjadi karena perbedaan spesies tanaman, pelarut, dan metode ekstraksi yang digunakan pada setiap penelitian.

\section{KESIMPULAN}

Hasil ekstrak kulit buah naga super merah (Hylocereus costaricensis) dapat dienkapsulasi dengan maltodekstrin yang menghasilkan mikrokapsul dengan rata-rata diameter partikel 14,24 $\mu \mathrm{m}$ dan efisiensi penyalutan tertinggi pada kecepatan pengadukan $800 \mathrm{rpm}$, yaitu $66,85 \%$. Aktivitas antiokskidan sebelum dan setelah terkapsulasi termasuk kategori sangat lemah dengan nilai $\mathrm{IC}_{50}$ sebesar 205,42 ppm untuk ekstrak dan 246,32 ppm untuk mikrokapsul.

\section{DAFTAR PUSTAKA}

Amar, A. A., Bahri, S., \& Mappiratu, M. (2018). Aktivitas Antioksidan Mikrokapsul Ekstrak Etanol Kapang Oncom Merah (Neurospora sp). KOVALEN: Jurnal Riset
Kimia, 4(2): 145-151. https://doi.org/10.22487/kovalen.2018.v4.i 2.11740

Cahyono, B. (2009). Buku Terlengkap Sukses Bertanam Buah Naga. Pustaka Mina, Jakarta.

Comunian, T. A., Thomazini, M., Alves, A. J. G., de Matos Junior, F. E., de Carvalho Balieiro, J. C., \& Favaro-Trindade, C. S. (2013). Microencapsulation of Ascorbic Acid by Complex Coacervation: Protection and Controlled Release. Food Research International, 52(1): 373-379. https://doi.org/10.1016/j.foodres.2013.03. 028

Handayani, M. N., Khoerunnisa, I., Cakrawati, D., \& Sulastri, A. (2018). Microencapsulation of Dragon Fruit (Hylocereus polyrhizus) Peel Extract Using Maltodextrin. IOP Conference Series: Materials Science and Engineering, 288, 012099. https://doi.org/10.1088/1757899X/288/1/012099

Hardi, J., Sugita, P., \& Ambarsari, L. (2013). Dissolution Behavior, Stability and AntiInflammatory Activity of Ketoprofen Coated Tripolyphosphate Modified Chitosan Nanoparticle. Indonesian Journal of Chemistry, 13(2): 149-157. https://doi.org/10.22146/ijc.21298

Hardjadinata, S. (2010). Budi Daya Buah Naga Super Red Secara Organik (1st ed.). Penebar Swadaya, Jakarta.

Irsyad, M. (2017). Produksi Antosianin Tersalut Maltodekstrin dari Kelopak Bunga Rosella (Hibiscus sabdariffa, L.) dan Aplikasinya dalam Pengolahan Pangan Fungsional. Mitra Sains, 5(1): 12-25.

Jaafar, R. A., Abdul Rahm, A. R. B., Che Mahmod, N. Z., \& Vasudevan, R. (2009). Proximate Analysis of Dragon Fruit (Hylecereus polyhizus). American Journal of Applied Sciences, 6(7): 1341-1346. https://doi.org/10.3844/ajassp.2009.1341. 1346

Manjanna, K. M., Kumar, T. M. P., \& Shivakumar, B. (2010). Calcium Alginate 
Cross-Linked Polymeric Microbeads for Oral Sustained Drug Delivery in Arthritis. Drug Discoveries \& Therapeutics, 4(2): 109-122.

Molyneux, P. (2004). The Use of The Stable Free Radical Diphenylpicryl- Hydrazyl (DPPH) for Estimating Antioxidant Activity. Songklanakarin J. Sci. Technol., 26(2): 211-219.

Neswita, E., Ben, E. S., \& Nofita, R. (2018). Mikroenkapsulasi Atenolol dengan Penyalut Albumin Menggunakan Metode Penguapan Pelarut. Jurnal Katalisator, 3(1):

19. https://doi.org/10.22216/jk.v3i1.3234

Nurliyana, R., Zahir, S., Suleiman, M., Aisyah, M., \& Rahim, K. K. (2010). Antioxidant Study of Pulps And Peels of Dragon Fruits: A Comparative Study. International Food Research Journal, 17: 367-365.

Pokorny, J., Yanishlieva, N., \& Gordon, M. (2001). Preparation of Natural Antioxidant, in Antioxidants in Food: Practical Applications (1st ed.). CRC Press, Cambridge.

Pranata, R., Wahdaningsih, S., \& Fahrurroji, A. (2014). Uji Aktivitas Antioksidan Fraksi Kloroform Kulit Buah Naga Super Merah (Hylocereus Lemairei Britton dan Rose) Menggunaka Metode DPPH (1,1-Difenil2-Pijrikhidrazil). Jurnal Mahasiswa Farmasi, Fakultas Kedokteran UNTAN, 1(1).

Pratama, N. (2017). Efisiensi Enkapsulasi Ekstrak Daun Avicennia Marina dengan Penyalut Maltodekstrin, Alginat, Maltodekstrin dengan Alginat Menggunakan Metode Freeze Drying. [Skripsi]. Universitas Brawijaya, Malang.

Priya, S., B., \& Preetha, R. (2016). Study on Color Stability and Microencapsulation of Anthrocyanin Pigment using Spray Drying. Biosciences, Biotechnology Research Asia, 13(2): 1207-1214. https://doi.org/10.13005/bbra/2154

Putri, N. K. M., Gunawan, I. W. G., \& Suarsa, I. W. (2015). Aktivitas Antioksidan Antosianin dalam Ekstrak Etanol Kulit Buah Naga Super Merah (Hylocereus costaricensis) dan Analisis Kadar Totalnya. JURNAL KIMIA, 9(2): 243-251.

Silitonga, P., \& Sitorus, B. (2014). Enkapsulasi Pigmen Antosianin dari Kulit Terong Ungu. Jurnal Kimia Katulistiwa, 3(1): 4449.

Sutriyo, S., Djajadisastra, J., \& Novitasari, A. (2004). Mikroenkapsulasi Propanolol Hidroklorida dengan Penyalut Etil Selulosa Menggunakan Metoda Penguapan Pelarut. Majalah IImu Kefarmasian, 1(2): 93-101. https://doi.org/10.7454/psr.v1i2.3373

Thies, C. (1996). A Survey Of Microncapsulation Process. Methods and Application. Marcel Dekker, New York.

Trojer, M. (2012). Modification of Microcapsules for Controled Release. [Skripsi]. Sweden.

Utama, D. A., Hariyadi, D. M., \& Hendradi, E. (2013). Pengaruh Kecepatan Pengadukan Terhadap Karakteristik Fisik Mikrosfer Ovalbumin-Alginat dengan Metode Aerosolisasi.

http://www.journal.unair.ac.id/filerPDF/Della \%20et\%20al,\%20ejurnal\%20submit2013.p df (diunduh tanggal 2 Januari 2020).

Widyastuti, W., Fratama, R. I., \& Seprialdi, A. (2015). Pengujian Aktivitas Antioksidan dan Tabir Surya Ekstrak Etanol Kulit Buah Naga Super Merah (Hylocereus costaricensis (F.A.C. Weber) Britton \& Rose). Scientia: Jurnal Farmasi dan Kesehatan, $\quad 5(2)$ : 69. https://doi.org/10.36434/scientia.v5i2.24

Winarno, F. (2017). Gastronomi Molekuler. Gramedia Pustaka, Jakarta.

Wu, L., Hsu, H.W., Chen, Y.C., Chiu, C.C., Lin, Y.I., \& Ho, J. A. (2006). Antioxidant and Antiproliferative Activities of Red Pitaya. Food Chemistry, 95(2): 319-327. https://doi.org/10.1016/j.foodchem.2005.0 1.002 